\title{
Effects of Speed, Curves, and Driver Behavior on Passive Securement Systems on Large Transit Buses
}

\author{
Andrea Mather and Katharine Hunter-Zaworski, Ph.D., P.E. \\ Oregon State University
}

\begin{abstract}
Wheeled mobility devices that are not secured properly on large transit vehicles pose risks to all passengers. The purpose of this study was to increase the understanding of the effects of horizontal and vertical curves, speed, and driver behavior on the safety and security of people using wheeled mobility devices in rear-facing passive containment systems on large transit buses. Testing included the use of manual wheelchairs and lightweight scooters on an articulated low-floor transit bus. The project conclusions were derived from data produced by accelerometers placed on the bus as well as visual observations of wheeled mobility device movement. The data showed a clear difference in the amount of movement of the wheeled mobility devices and the comfort of the seated passenger when the bus traveled on a combination of horizontal and vertical curves at different driving speeds.
\end{abstract}

Keywords: Wheeled mobility devices, rear facing containment, bus dynamics

\section{Introduction}

The securement of wheeled mobility devices (WhMDs) on transit buses is required under the transportation regulations associated with the Americans with Disabilities Act (ADA) (ADA 1998). Since the enactment of the ADA, securement systems have been studied, designed, and deployed to increase passenger safety, security, and comfort. Large transit buses are equipped with two types of securement systems: active and passive. Common active securement systems include auto docking systems or belttype tie-downs. Active systems that have belts or straps usually require a second person to attach them to the wheeled mobility device. This often increases dwell time at bus stops and encroachment on the personal space of the passenger. 
WhMDs on large transit buses that have a gross vehicle weight greater than 26,000 pounds are required to be equipped with one forward-facing belt-type securement in addition to any rear-facing containment systems. The belt-type securement systems usually require another person, often the driver, to secure the WhMD appropriately. This often increases the vehicle dwell time at stops and can influence the transit schedule. Rear-facing passive systems are designed to allow the passenger to secure himself or herself without the assistance of another person. These containment systems have widespread use in Europe and Canada (Hunter-Zaworski and Rutenberg 2014).

This study focused on rear-facing passive containment systems that are deployed on transit buses that travel on mixed right-of-way streets with both horizontal and vertical curvature.

\section{Background}

In 2001, a survey conducted by the University of South Florida found that all 94 transit agencies included in the study used a belt securement system (Foreman and Hardin 2002). In 2013, Frost et al. found that for the past 20 years, forward-facing belt-type securement systems were the most common securement system in the U.S. on large transit vehicles. The researchers also found that only $7.5 \%$ of trips made by people in manual chairs used securement systems (Frost et al. 2013).

Intersections that are designed for large transit vehicles have recommended geometric design dimensions set forth by the American Association of State Highway and Transportation Officials (AASHTO). The AASHTO Guide for Geometric Design of Transit Facilities on Highway and Streets states that the maximum grade for roadways on which transit vehicles operate is 10\%, but it recommends a lower grade (AASHTO 2014). Tables 1 and 2 show AASHTO's standard bus design characteristics and bus performance characteristics.

TABLE 1.

\begin{tabular}{|l|c|c|c|}
\hline \multirow{2}{*}{\multicolumn{1}{c|}{ Item }} & \multicolumn{2}{c|}{ Regular Bus } & Articulated Bus \\
\cline { 2 - 4 } & $40 \mathrm{ft}$ & $45 \mathrm{ft}$ & $60 \mathrm{ft}$ \\
\hline Gross Weight & $36,900-40,000 \mathrm{lbs}$ & $55,200 \mathrm{lbs}$ & $66,600 \mathrm{lbs}$ \\
\hline Turning Radius Inside & $24.5-30 \mathrm{ft}$ & $24.5-30 \mathrm{ft}$ & $27.3 \mathrm{ft}$ \\
\hline Turning Radius Outside & $42.0 \mathrm{ft}-47 \mathrm{ft}$ & $42.0-47 \mathrm{ft}$ & $39.8-42 \mathrm{ft}$ \\
\hline
\end{tabular}

Source: AASHTO, Guide for Geometric Design of Transit Facilities on Highways and Streets, 2014 
TABLE 2.

AASHTO Bus Performance Characteristics

\begin{tabular}{|l|c|c|c|}
\hline & MPH/Sec & Ft/Sec & g's \\
\hline Acceleration & & & 0.15 \\
\hline $0-10 \mathrm{sec}$ & 3.33 & 4.9 & 0.10 \\
\hline $10-30 \mathrm{sec}$ & 2.22 & 3.3 & 0.04 \\
\hline $30-50 \mathrm{sec}$ & 0.95 & 1.4 & $0.09-0.14$ \\
\hline Deceleration & $2-3$ & $2.9-4.4$ & $0.27-0.54$ \\
\hline Normal & $6-12$ & $8.8-17.6$ & \\
\hline Maximum & \multicolumn{3}{|c|}{$6 \%$} \\
\hline Maximum Grade (Sustained Roadway) & $10-12 \%$ & \\
\hline Maximum Grade (Short Upgrade) &
\end{tabular}

Source: AASHTO, Guide for Geometric Design of Transit Facilities on Highways and Streets, 2014

Researchers developed guidelines for transit operations at standard operating speeds around corners. This includes guidelines from transit districts and departments of education (school buses) (Kentucky Department of Education 2008). These recommendations are 10 miles per hour $(\mathrm{mph})$ for turns and $15 \mathrm{mph}$ for evasive maneuvers (MUTD 2011).

\section{Objectives and Motivation}

Lane Transit District (LTD) in Eugene, Oregon, approached the research team with questions concerning several major intersections in its operating system and the performance of rear-facing passive containment systems. The primary objective of the research was to determine the relationship between horizontal and vertical curves and speed and the effect on passive containment for WhMDs on large transit vehicles. This relationship is very complex, with multiple factors interacting with each other. The study was designed to isolate several key factors in the field tests.

\section{Description of Testing}

Testing was conducted in partnership with LTD using LTD buses. LTD operates vehicles in demand-responsive paratransit, fixed-route, and bus rapid transit (BRT) services. The project focused on buses operating in fixed-route and BRT operating modes. Vehicle testing occurred over two days, the first in February 2015 and the second in October 2015. Testing included driving trials at the maintenance facility and roadway tests on regular transit routes that included steep hills and sharp turns. The purpose of testing in the yard was a controlled study of horizontal turning maneuvers. Testing conducted in the maintenance yard calibrated the data acquisition equipment and validated testing assumptions related to horizontal curves. The test drives on the roadway included sharp horizontal and steep vertical curves. 


\section{Horizontal Curve Testing}

To study the acceleration and WhMD behavior in horizontal curves, tests were conducted in LTD's parking lot in Springfield (Figure 1). This provided the research team with the opportunity to conduct sharp horizontal turning maneuvers on a level grade. The bus made sharp left turns at the places indicated by the number 2 on Figure 1 and slalom turns through the parking lot down the lanes indicated by the number 1 . The parking lot was mostly empty during the testing and was similar to the configuration shown in Figure 1. This allowed the driver to make sharp turns to demonstrate the worst-case scenario.

FIGURE 1.

Aerial view of flat parking lot used to test horizontal curves

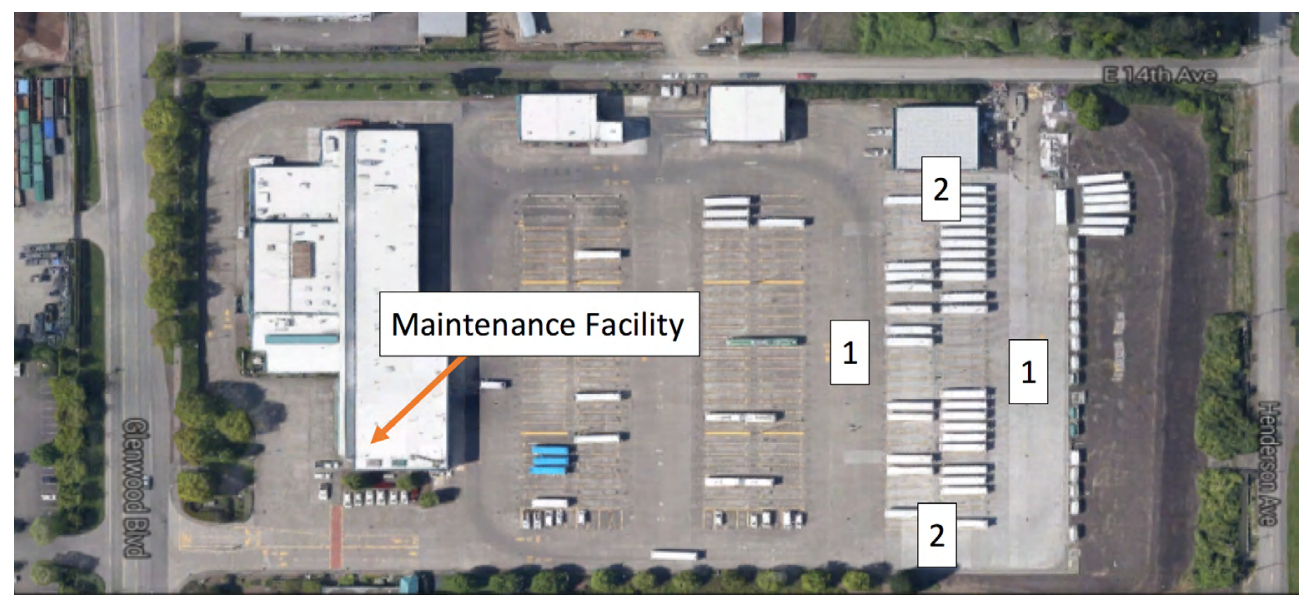

$1=$ location of $\mathrm{S}$ turns, 2 = sharp left turns

Source: Google Maps

\section{Testing on Horizontal and Vertical Curves}

The vertical and horizontal curve driving tests were conducted at a highway interchange in Eugene that has a mix of steep vertical and sharp horizontal curvature and a signalized intersection. The section of roadway is at the end of a highway overpass that includes a signalized intersection followed by a left turn onto a downgrade ramp. This intersection was of particular interest because of the combination of vertical and horizontal curvature and a signal-controlled intersection. This intersection is the location of a prior incident involving LTD passengers seated in WhMDs who were secured in an active forward-facing securement systems that resulted in the WhMD tipping over. The bus traveled on the overpass westbound on Goodpasture Island Road, followed by a downgrade to the signal. The intersection has one through/left lane (no right turn).

\section{Test Methodology}

The accelerometers were placed in a longitudinal orientation on the floor of the bus to collect three-dimensional acceleration data. The acceleration data collection was 
independent of the type of WhMD. During the bus testing, two different WhMDs were occupied by a 50-percentile male anthropometric test dummy (TED) sitting in the seat. The test dummy was used in these data collection activities to minimize human subject risk. The WhMD types included a standard manual chair and a three-wheeled scooter. The scooter used in the testing was similar to models that can be bought without a prescription at a non-medical supply store and is representative of WhMDs that many passengers use when riding LTD vehicles. The center of gravity of the scooter was higher off the ground than the manual chair and more prone to tipping over; the majority of the tests used the scooter for this reason. Some of the initial tests in the maintenance yard used the manual chair with the test dummy sitting in the wheelchair. Both WhMDs were in good working condition.

In all tests, the WhMDs had the brakes set on the device or powered down. Research has shown that during revenue service, passengers do not consistently set the brake on their devices. The research team conducted previous research on other transit vehicles that showed that setting the brake has a significant impact on the movement of WhMDs. For the safety of the research team in this study, the brakes were set. The mobility of TED also was restricted to folding his arms in his lap. Prior testing showed that TED is much more stable when he puts an arm on the folded-up seat. The position of TED's arms was intentionally included to evaluate a passenger who has no upper body strength or control. Figure 2 illustrates the placement of TED's arms during testing and shows a manual wheelchair in the rear-facing containment with the aisle sidearm lowered. Passengers have the potential to increase their stabilization if they have mobility and strength in their upper body.

All the testing used a rear-facing passive containment system that is located directly behind the driver. The passenger is rear-facing, with the back of his WhMD touching the backboard of the system. The system also features containment on three sides, with a bar that extends from the back on the aisle side and a folded seat on the window side. Figure 2 shows TED in the rear-facing containment location and sitting in a wheelchair.

FIGURE 2.

TED in wheelchair in passive rear-facing containment

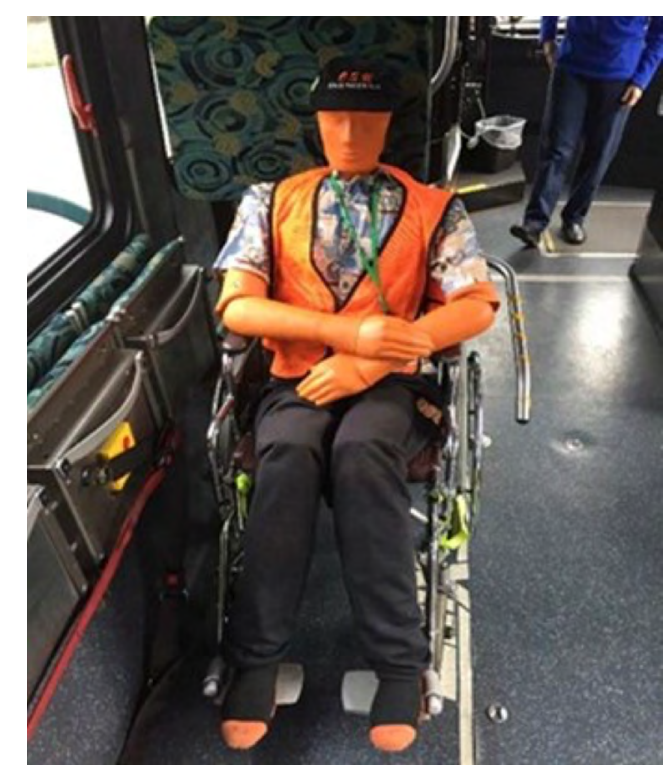


To increase stability, the passenger may use the back of the folded seat. Figure 3 shows TED in the rear-facing containment location and sitting in a scooter.

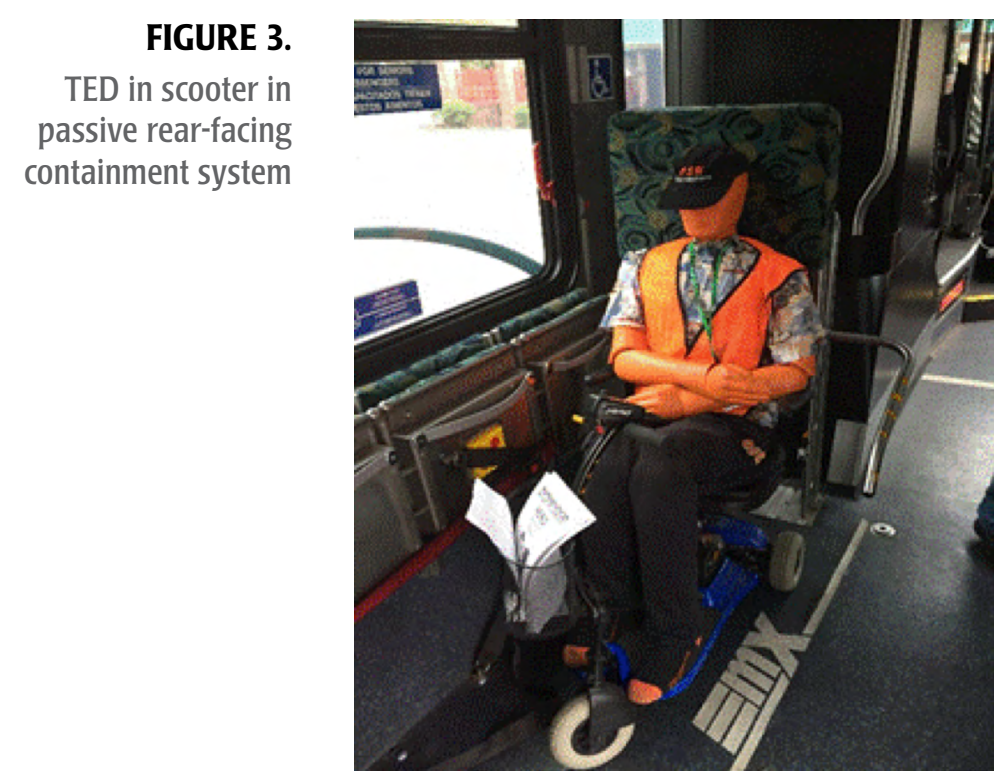

The study included two forms of data collection: observations and accelerometers. Each of the researchers and officials from LTD conducted observations. One researcher was located next to the securement system and one in the middle of the bus to allow for multiple viewing angles during testing. Taking photos occurred only before and after testing for reference of orientation and experimental design.

Data were collected for this study using Gulf Coast Data Concepts Model X2-2 USB Accelerometers, shown in Figure 4. The placement of the accelerometers included locations before the vehicle articulation point and over the wheel well. The accelerometers recorded acceleration in three axis directions (axial, longitudinal, vertical) with a $32-\mathrm{Hz}$ sample rate. For redundancy in data, data were collected from two accelerometers. Also used during data collection were time stamps on the accelerometers and GPS tracking. Figure 4 shows the location of the accelerometers.

FIGURE 4.

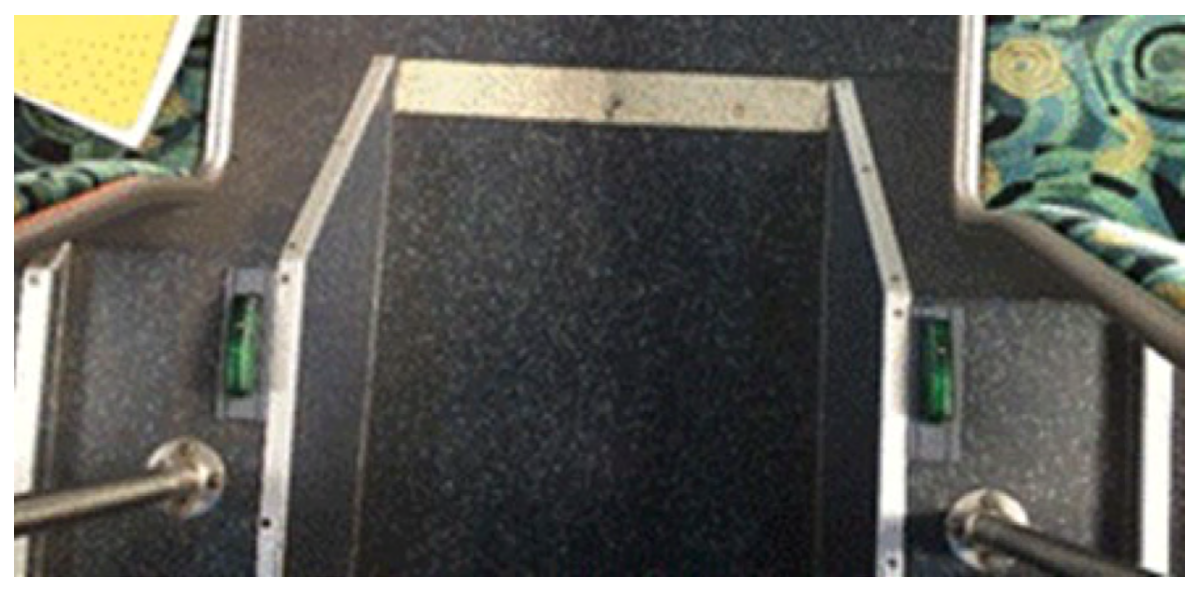


Consistent weather conditions prevailed during both days of testing-clear with no rain or moisture on the roadway. During each day of testing, the same operator drove for all tests, but there were different operators in February and October. The operator during the February testing was from the LTD Maintenance Department and was very familiar with the performance of the vehicle. The operator in the October testing was a veteran driver who was also an instructor and operator trainer.

The study used an articulated low-floor bus designed for the BRT system. The only people on the bus during the time of testing were researchers and LTD Risk Management staff. The crash dummy occupied the WhMD during the entirety of the testing. Severe cornering test runs were conducted only at the LTD maintenance facility. Figure 5 shows an LTD Emerald Express Bus used for BRT service (EmX) and is similar to the one used in the study.

FIGURE 5.

Example of type of bus used for tests

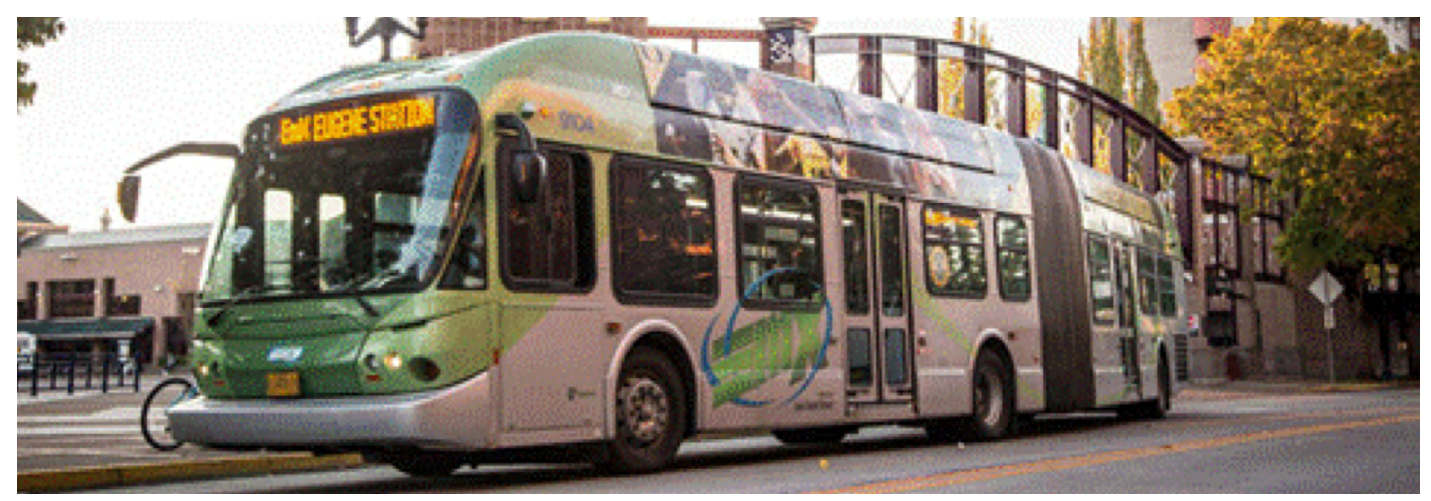

Photo courtesy of Lane Transit District

Table 3 summarizes the experimental conditions, showing information for both days of testing and data collection locations.

TABLE 3.

Summary of Variables Used in Testing

\begin{tabular}{|l|l|l|}
\hline \multicolumn{1}{|c|}{ Equipment } & \multicolumn{1}{|c|}{ Variable } & \multicolumn{1}{c|}{ Description } \\
\hline Bus & Constant & Low-floor articulated BRT bus \\
\hline Wheeled Mobility Device & Variable & $\begin{array}{l}\text { Lightweight three-wheel scooter (powered off) and } \\
\text { standard wheelchair with brakes applied }\end{array}$ \\
\hline Data Collection System & Constant & $\begin{array}{l}\text { Accelerometers placed in same location and } \\
\text { collection rate. }\end{array}$ \\
\hline Test Location & Variable & $\begin{array}{l}\text { Flat maintenance yard to isolate horizontal curves } \\
\text { and Goodpasture Island Road intersection to study } \\
\text { both vertical and horizontal curves }\end{array}$ \\
\hline Driver & Constant/Variable & $\begin{array}{l}\text { Driver stayed constant for day, but different drivers } \\
\text { used in February and October tests }\end{array}$ \\
\hline Speed of Curves & Variable & $\begin{array}{l}\text { Curve speed changed to show difference between } \\
\text { recommended speed and extreme speed }\end{array}$ \\
\hline
\end{tabular}




\section{Study Limitations}

LTD has only rear-facing passive containment on the large articulated buses used in its BRT service. Rear-facing containment is very popular with passengers who use wheeled mobility devices, and LTD is considering installing rear-facing containment systems on its new non-articulated buses. Limitations to the study included using only one type of bus and only regular or moderately-severe driving conditions. Future testing should consider using non-articulated transit buses to expand the applicability of the results.

The nature of the data collection process in the field limits the isolation of all contributing factors and conditions. Different tests were used to isolate some factors, but not all factors could be limited in the field.

\section{Results}

The results of this study were divided into three segments: isolated horizontal curves, combination of horizontal and vertical curves, and driver behavior. Calibration tests for the accelerometers were conducted before the start of the testing. The results of the study were derived from the accelerometer data from the bus and observations made by research team.

\section{Horizontal Curves}

The graph in Figure 6 is from the tests conducted at the bus parking lot at the LTD maintenance facility. The data from the three axis accelerometers show the very low acceleration rates during slow speed and increasing to the maximum safe speed on horizontal curves. The lower speeds were $5 \mathrm{mph}$ and increased to approximately 15 $\mathrm{mph}$. The researchers observed no movement during the test of the manual wheelchair that was occupied with TED. The testing was completed in a single session.

FIGURE 6.

Results of low-speed

(5-15 mph) S-curve tests conducted at LTD maintenance facility

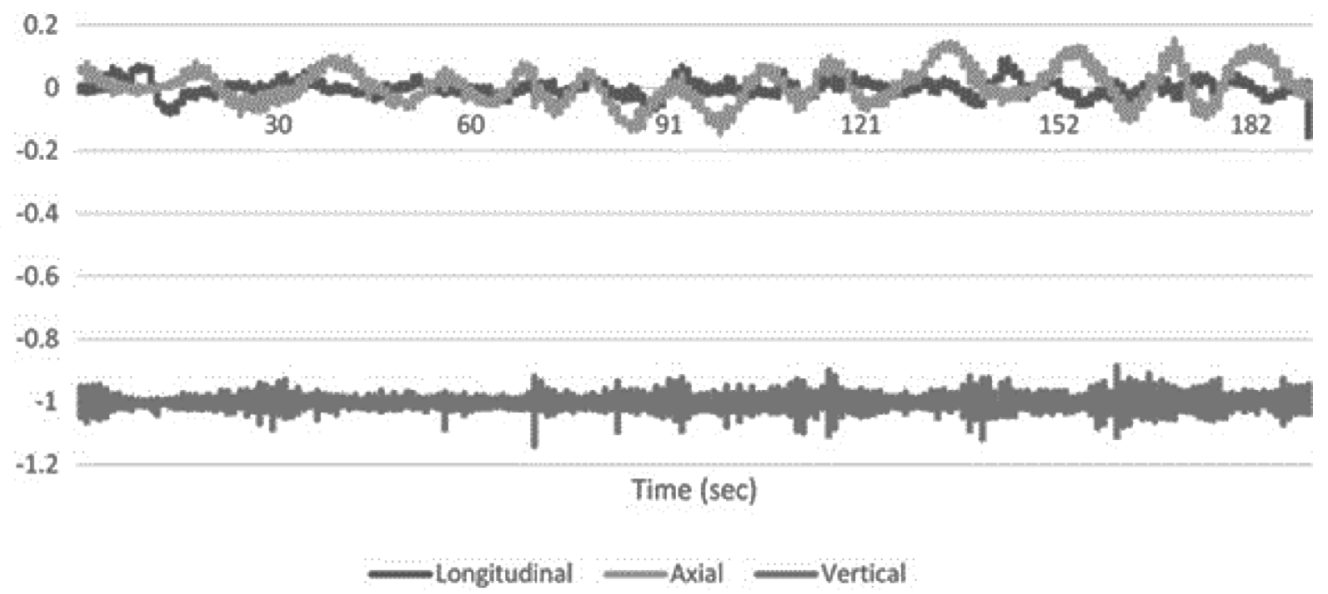


Since acceleration is the rate of change of velocity, as the speeds changed during cornering, this was reflected in the accelerations. Figure 6 shows the lateral acceleration resulting from the " $\mathrm{S}$ " cornering. The vertical acceleration measured the "bumps in the road," and the forward or longitudinal acceleration measured the changes in speed until the bus came to a complete stop (183 sec).

Observations of TED showed very little to no movement throughout the testing of the isolated horizontal curvature. The test dummy's movement was very limited to within the containment system and did not cause any alarm for safety.

\section{Vertical and Horizontal Curves}

The second group of tests conducted included a vertical curve and a horizontal curve at the interchange of Goodpasture Island Road and Delta Highway in Eugene. Three data collection tests were conducted under the conditions of low speed, high speed, and excess speed on cornering that caused the WhMD to tip within the containment system. Each of the speed tests was conducted only once due to time limitations.

Accelerometer data, as shown in Figure 7, illustrates the accelerations of the bus at a low speed $(5 \mathrm{mph})$ while navigating the horizontal and vertical curvature. The change in acceleration was the smallest of any of three tests. The slower speed has the smallest amount of acceleration. This test also had the lowest difference in maximum longitudinal and axial acceleration. Observations of the TED and the WhMD within the containment system were limited to little to no movement.

FIGURE 7.

Low-speed (5 mph )

no-movement

acceleration data

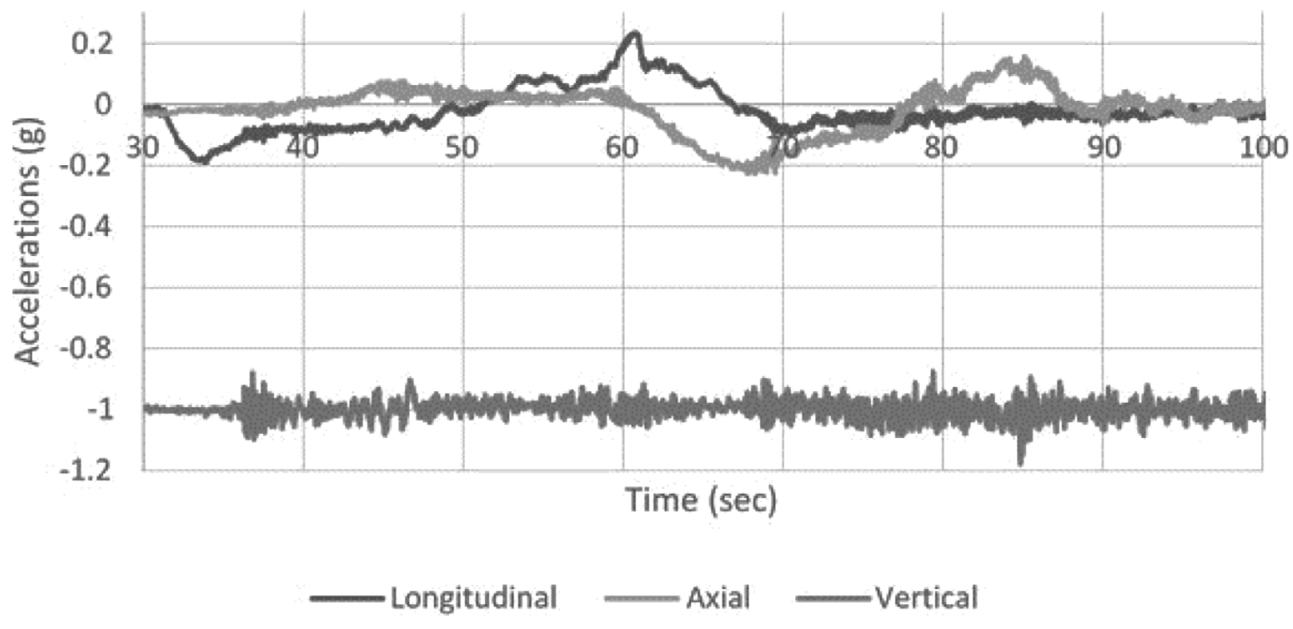

The higher-speed ( $14 \mathrm{mph}$ ) test - the highest speed a professional driver would driveshowed minimal movement of the WhMD. This movement would typically occur in regular revenue service operations and likely would not cause injury to a passenger. When compared to the low-speed test, the higher-speed test had much larger changes in the maximum longitudinal and minimum axial acceleration. The changes in acceleration also produced a larger jerk during the turning maneuver. The accelerations of the vehicle are shown in Figure 8. 
FIGURE 8.

Higher-speed (14 mph) slight-movement acceleration data

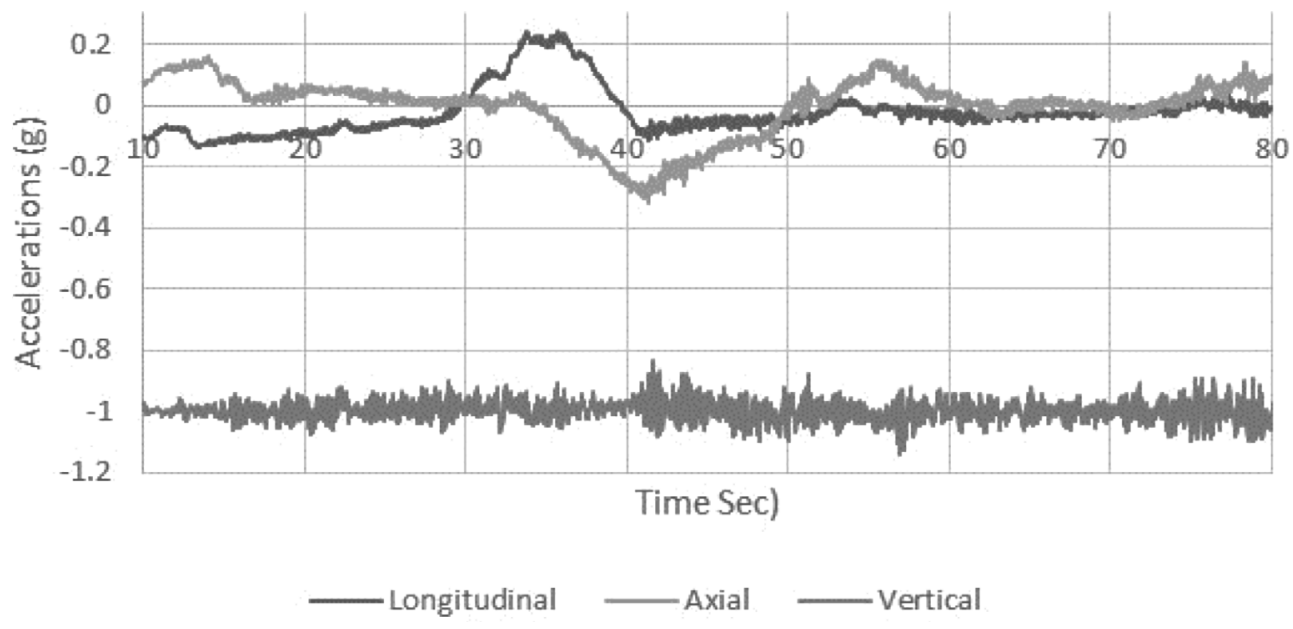

Figure 9 shows the accelerations when the wheeled mobility device tipped over and also illustrates the higher levels of acceleration. The jagged lines show that the changes in accelerations were sudden. At approximately the 70-sec mark, a spike in the acceleration occurred. This was when the bus started from the stop line at the intersection and also is when the wheels at the front of the WhMDs moved in the direction of the tipping. The maximum acceleration occurred in the middle of the turn. The side-to-side motion of the test dummy induced some of the motion of the WhMD, which caused the test dummy to shift weight off center and start to tip over. The tipping also was due to the high center of gravity of the scooter with a $50 \%$ test dummy.

FIGURE 9.

High-speed test that tipped WhMD accelerations data

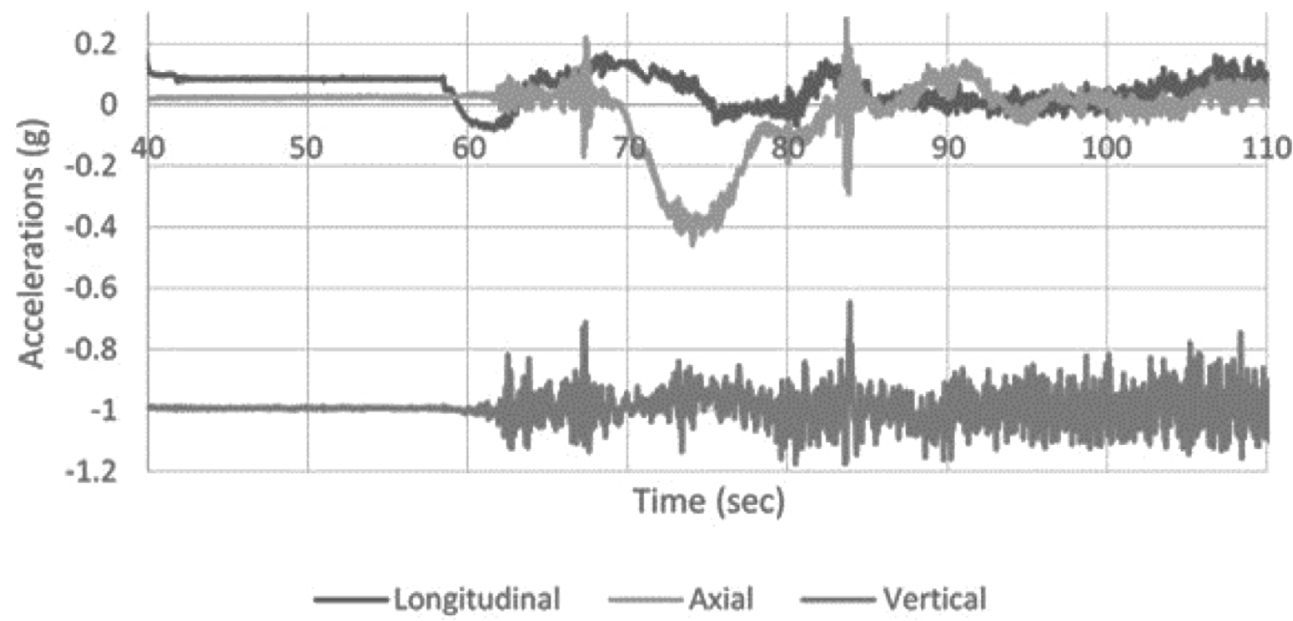

\section{Driver Performance}

Different drivers drove the bus on each day of testing. On the first day, the driver was from the LTD Maintenance Department and was very experienced with performance of the bus used in testing. On the second test day, the driver was very experienced with the bus and was a professional operator with more than 20 years' experience as a commercial vehicle operator and also was a bus operator trainer. The differences in 
how each driver completed turns were shown in the accelerometer data. The first day of testing was designed to look at the maximum or most severe driving conditions. The operator drove close to the top level of vehicle performance to simulate severe driving operations. At the intersection of interest, the driver drove through the corner at a high speed. Both the high speed and sudden changes in direction caused the WhMD to become unstable and tip. On the second day of testing, the professional driver completed all the driving trials within the standard driving parameters. In addition, he called out the speed that he took the corners. The testing began at the low speed, and no movement of the WhMD or TED was observed. During the higher-speed tests, there was still very little movement of WhMD or TED. The data also showed that the driver still drove through the curves very smoothly. The research team observed a higher level of passenger comfort (less motion sickness) when the professional driver drove the corners at the suggested speeds that are used in operator training.

\section{Conclusions and Recommendations}

This study showed that passive rear-facing containment systems for WhMDs are adequate for preventing users from tipping when the bus is operated within normal driving parameters. This also assumes that the passenger and the WhMD have the brakes applied or are powered off and that the WhMD fits in the containment space. The WhMD also must be constrained, with the back of the WhMD near or touching the backboard of the passive containment area. Information about proper use of the rearfacing containment area should be placed on placards on board so users understand correct use and the consequences for using the system improperly.

Transit operators need to understand the implications of driver behavior on the safety and comfort of all passengers. The acceleration data showed the influence of the driving style of the operator. Driver style during turns was found to be a contributing factor to tipping. This was an unexpected factor. On the first day of testing, a driver from the LTD Maintenance Department operated the bus with the intent to simulate severe driving. On the second day of testing, a professional driver and operator trainer drove the bus with the intent to study normal operations. The difference in the smoothness of the curves was obvious, as shown in the accelerometer data and visual observations.

In the $5 \mathrm{mph}$ and $14 \mathrm{mph}$ tests, the rate of change of acceleration was more gradual; in the tipping test, the rate of change of acceleration was much more rapid and showed greater changes in acceleration in all of the directions. The severe driving was more erratic. Even though speed data were not collected in the tipping, a post-testing interview with the driver led the researchers to believe that the speed was about 20 mph during the tipping test.

In summary, passive rear-facing containment systems are adequate for most roadway geometries, with the assumption that drivers operate the vehicle at the prescribed speeds for the roadway geometrics. 


\section{Future Research}

The results of this study were shared with LTD, but additional research should be conducted on this topic. The impact of driving style was a surprising and unintended outcome of this study. Targeted research to isolate the characteristics of an "expert" driver and the impact on accelerations would produce better training and best practices for operators. In this study, using only one intersection limited the conclusions. Additional roadway geometry types, intersection types, and types of vehicles are needed to determine the extent of the effects of the combination of vertical and horizontal curves on passive securement systems on large transit buses.

\section{References}

American Association of State Highway and Transportation Officials (AASHTO). 2014. Guide for Geometric Design of Transit Facilities on Highways and Streets. Washington, DC.

Americans with Disabilities Act (ADA). 1998. "Accessibility Specifications for Transportation Vehicles." 49 CFR Part 38.

Federal Transit Administration. 2013. "Questions and Answers Concerning Wheelchairs and Bus and Rail Service." http://www.fta.dot.gov/12325_15055.html.

Foreman, C., and J. Hardin. 2002. "The Challenges of Wheelchair Securement: Searching for Solutions." Bus and Paratransit Conference Proceedings, 3-17, http://www.nctr.usf. edu/pdf/Wheelchair\%20Securement.pdf.

Frost, K. L., G. Bertocci, and S. Zdravko. 2013. "Wheelchair Securement and Occupant Restraint System (WTORS) Practices in Public Transit Buses." Assistive Technology (RESNA), 25(1): 16-23. doi:10.1080/10400435.2012.680660.

Hunter-Zaworski, K. M., and J. R. Zaworski. 2005. "TCRP IDEA Report 38: Assessment of Rear Facing Securement on Bus Rapid Transit." Transit Cooperative Research Program, Washington, DC.

Hunter-Zaworski, K. M., and U. Rutenberg. 2014. "TCRP Report 171: Use of Mobility Devices on Paratransit Vehicles and Buses." Transit Cooperative Research Program, Washington, DC.

Kentucky Department of Education, Pupil Transportation Branch. 2008. Driver Instructor Training Manual.

Missoula Urban Transportation District (MUTD). 2011. Transit Guidelines in Project Development. 


\section{About the Authors}

ANDREA MATHER, EIT (andrea.j.mather@gmail.com) received an M.S. in Civil Engineering (2016) and a B.S Civil Engineering in (2014) from Oregon State University.

Katharine Hunter-Zaworski, Ph.D., P.E. (hunterz@engr.orst.edu) is an Associate Professor of Civil Engineering at Oregon State University and an internationallyrespected expert in accessible public transportation. 